\title{
Laparoscopic cholecystectomy: An experience at College of Medical Sciences, Teaching Hospital, Bharatpur Nepal
}

S. Kumar' ${ }^{1}$ B. N. Patowary ${ }^{2}$, S.Hirachan ${ }^{3}$, P. Shrestha ${ }^{4}$

${ }^{1}$ Lecturer, ${ }^{2}$ Professor and Head, ${ }^{3,4}$ Resident, Department of General Surgery, College of Medical Sciences, Bharatpur, Chitwan, Nepal

\begin{abstract}
Laparoscopic cholecystectomy is the "gold standard" for benign gallbladder diseases. Laparoscopic cholecystectomy has rapidly gained popularity and it is one of the commonly performed operations in Nepal. Laparoscopic Cholecystectomy first performed by Muhe in 1985. The current descriptive study is carried out in Department of General Surgery, College of Medical Sciences - Teaching Hospital (CMS-TH), Bharatpur to evaluate the result of Laparoscopic Cholecystectomy in symptomatic gallstones disease in our set up with special emphasis on complication rate, morbidity and mortality. The data of all patients who underwent laparoscopic cholecystectomy form March 2008 to March 2009 was entered in standardized proforma and analysed on SPSS 10. Out of 110 patients, 85 (77.27\%) were female and 25 (22.73\%) were males; the age range from 17 to 70 years mean age being 41.30 years, majority were in age $25-40$ years group. Eight (7.2\%) patients had bile leak, 2 (1.8\%) patients developed port site wound infection. There was no bile duct or colonic injuries. The conversion rate was $7.2 \%$ (in 8 patients). There was no mortality.
\end{abstract}

Key Words: Laparoscopic cholecystectomy, morbidity, bile duct.

\section{Introduction}

Gallstone disease is a major health problem worldwide particularly in the adult population. ${ }^{1}$ The prevalence of gallstones in the United States is around $10 \%$ to $15 \%$ amongst white males and in Europe around 18.5\%. ${ }^{2}$ The traditional open cholecystectomy performed for the first time in 1882 by Carl August Langerbach ${ }^{5}$ has been replaced by laparoscopic cholecystectomy (LC), first performed by Muhe in 1985, which has revolutionized the treatment of gall bladder disease and is now the gold standard for the treatment of gallstones

Correspondences: S. Kumar

E-mail:drsujit1755@gmail.com and the commonest operation performed laparoscopically worldwide., ${ }^{2,3}$ It causes less surgical trauma thereby resulting in reduced hospital stay and early resumption to normal activity. ${ }^{4}$ The current reviews show clear benefit of laparoscopic cholecystectomy over open cholecystectomy in terms of intra operative, intra hospital and long term morbidity. ${ }^{5,6,7}$ Most patients with symptomatic gallstones can go for laparoscopic cholecystectomy, provided they can tolerate general anesthesia and do not have serious cardiopulmonary disease or other comorbid conditions that preclude surgery. Generally, the indications for laparoscopic cholecystectomy are similar 
S. Kumar et al Laparoscopic cholecystectomy: An experience at

to those for open cholecystectomy. Patients with generalized peritonitis, septic shock due to cholangitis or other causes, severe acute pancreatitis, end stage cirrhosis of liver with portal hypertension, severe coagulopathy unresponsive to treatment, known cancer of gallbladder and cholecystoenteric fistula are not the candidates for laparoscopic cholecystectomy. ${ }^{8}$

\section{Materials and methods}

This descriptive study was carried out in surgery department of CMS-TH from March 2008 to March 2009 over a period of one year. Patients of either sex, more than 13 years of age who underwent laparoscopic cholecystectomy were included in the study. The patients who had jaundice, mass or dilated common bile duct (CBD)(>10 mm in diameter) and hepatitis B or $\mathrm{C}$ positive patients were excluded. All patients were admitted and necessary preoperative workup including complete blood count, urea, creatinine, blood sugar, liver function tests and Hepatitis B and C screening were done. Ultrasound abdomen was done in each patient to confirm gallstones and to assess the CBD diameter and was used as a tool for exclusion criteria. Chest X-ray and ECG were done if the patient was above fourty years. Standard four-port technique was used in $80 \%$ of the cases and in rest of the patients three port was used.. The pneumoperitonium was created by closed method by using Veress needle in 60 patients and in 55 patients by open technique. All the data about patient was recorded on standardized proforma and analysed by SPSS 10.

\section{Results}

Out of 110 patients, 85 (77.27\%) were female and 25 (22.73\%) were males giving rise to a female to male ratio of 3.4:1. The age ranged from 17 to 70 years mean age being 41.30 years, majority were in fourth (31.66\%) and fifth (25\%) decade of life. Majority of the patients 79 (71.8\%) had multiple, 26 (23.6\%) had single stone while 5 (4.5\%) had polyp in the gall bladder. The status of the gall bladder as observed in this study is given in Table-1. Eight (7.2\%) patients had bile leak, 2 (1.8\%) patient developed port site wound infection. There was no bile duct or colonic injuries. The conversion rate was $7.2 \%$. In five patients the conversion was due to fibrous adhesions, due to technical problem in one and empyema gall bladder in the other two. Operative time in most of the patients was between 60 minutes to 90 minutes (Table-2). In most of the patients standard 4 ports were used (Table-3). Drain was placed in Morrison's pouch in 75(68.18\%) patients (Table-4). The post-op hospital stay was $1-5$ days, mean stay being 1.63 days. There was no mortality.

\section{Table-1: Per operative status of gall bladder}

\begin{tabular}{lcc}
\hline Gall bladder & No of patients & \% \\
\hline Acutely Inflamed & 8 & 7.2 \\
Chronic Inflammation - & 45 & 40.9 \\
Mucocele & 5 & 4.5 \\
Normal & 52 & 47.2 \\
\hline
\end{tabular}


Table-2: Operative time

\begin{tabular}{lcc}
\hline Time & No of patients & \% \\
\hline Less than 60 minutes & 54 & 49.09 \\
60 to 90 minutes & 35 & 31.81 \\
90 to 120 minutes & 17 & 15.45 \\
120 to 180 minutes & 04 & 3.6 \\
\hline
\end{tabular}

Table- 3

\begin{tabular}{lcc}
\hline Ports used & No of patients & \% \\
\hline 3 ports & 21 & 19.09 \\
4 ports & 89 & 80.9 \\
\hline
\end{tabular}

Table- 4

\begin{tabular}{lcl}
\hline Drain & No of patients & $\mathbf{\%}$ \\
\hline Used & 75 & 68.18 \\
Not used & 35 & 31.8 \\
\hline
\end{tabular}

\section{Discussion}

Since 1985, when first laparoscopic cholecystectomy was performed, there is continuous decrease in no. of open cholecystectomies. Now in developed countries less than $20 \%{ }^{9,10}$ of the total cholecystectomies are performed by open method. In developing countries like Nepal the open cholecystectomy is still common. The present study elaborates the early experience of laparoscopic cholecystectomy in terms of morbidity and mortality. No surgical procedure is without having complications. Iatrogenic bile duct injuries have long been a matter of concern and debate; and laparoscopic cholecystectomy has been associated with an increase in the incidence of operative bile duct injuries. ${ }^{11,12}$ Strasburg et al in 1995 showed an incidence of iatrogenic bile duct injury of $0.125 \%$ and $0.55 \%$ during open and laparoscopic cholecystectomy respectively. So incidence of bile duct injury is 2-4.5 times higher than in open technique but in present study there was no bile duct injury. In our study majority (77.27\%) of the patients were female which is consistent with the national ${ }^{19}$ and international papers. ${ }^{5-7,12-14}$ Mean age and minimum age was slightly less than reported in the literature. ${ }^{13,19,20}$ Review of national and international data shows a conversion rate of $5 \%$ where as it is up to $30 \%$ in various studies. ${ }^{14}$ The conversion rate is high amongst studies from developing countries 1,8-11,21,22 when compared to the studies from developed countries. ${ }^{12-14,17,18}$ Our study concluded the conversion rate of $7.2 \%$, which is higher than other studies. The reason for conversion was dense adhesion in five cases, empyema of gall bladder in two cases and technical error in one case. The other reason reported in the literature are haemorrhage in Calot's triangle, slipped ligature \& clips, gangrenous patches in the fundus, partial transection of the CBD, injury to the stomach, and bilio-digestive fistula. ${ }^{1,15,21,22}$ We did not encounter any of these problems in our series. In this study 9 
S. Kumar et al Laparoscopic cholecystectomy: An experience at

(8.1\%) gall bladders were perforated. Which is comparable to other studies. ${ }^{22}$ The situation was handled by applying clips or holding the perforation site by grasper. Port site wound infection occurred in 2 (1.8\%) patients. This is reported $2.2 \%{ }^{10}$ and $1.63 \%{ }^{25}$ elsewhere. This infection required no special measures except regular dressing. In this study 8(7.2\%) patients had bile leak and all had drain in Morrison's pouch. Bile leak was seen in first postoperative day and stopped by the end of $5^{\text {th }}$ to $6^{\text {th }}$ postoperative day. Average operating time in present study was 60 to 120 minutes which is higher than other studies. ${ }^{11,22,21}$ This may because of learning curve. We kept drain in $75 \%$ of cases because of increase incidence of bile leak. The hospital stay in present study was 1 to 5 days with mean 1.69 which was comparable to other studies. 21, 22, 23

\section{Conclusion}

Laparoscopic Cholecystectomy is a safe and effective procedure in our set up and is up to the accepted standard as compared to national and international studies. Proper training of the young surgeons and availability of equipments are the main areas of concern.

\section{References}

1. G..D. Friedman. Natural history of symptomatic and asymptomatic gallstone. Am J Surg 1993; 165: 399.

2. S. Adamsen, O.H. Hansen, P. Funch-jensen. Laparopscopic cholecystectomy: A prospective nationwide series. J Am Coll Surg 1997; 184: 571.

3. J. Barkun, A. Barkun, J. Sampalis : Randomised controlled trial of laparoscopic versus mini cholecystectomy. Lancet. 1992; 340:1116-9.

4. F. Dubois, .P Icard, G. Bertelot. Coelioscopic Cholecystectomy. Preliminary report of 36 cases. Ann Surg 1990; 211: 60-2.
5. T.R. Gadaor, M. A. Talamzii. Traditional vs Laparoscopic cholecystectomy. Am J Surg.1999;161:336-8.

6. A. Cuschieri. Laparoscopic cholecystectomy. J R Coll Surg Edinb.1999;44:187-92.

7. W. Ji, L.T. Li, J.S. Li. Role of laparoscopic subtotal cholecystectomy in the treatment of complicated cholecystitis. Hepatobilpancreatic Dis Int.2006;5(4):584-9.

8. T. Saeed, M. Zarin, M. Aurangzeb, et al. Comparative study of Laparoscopic versus open Cholecysyectomy. Pak J Surg Jun 2007;23(2):96-9.

9. F.G. Bhopal, M.A. Rai, M.A. Iqbal. A comparative study of morbidity in laparoscopic and open cholecystectomy. J Surg Pak. 1998;3(3):2-7.

10. National Institute of Health Consensus Development Conference Statement on Gallstones and Laparoscopic Cholecystectomy. Am J Surg 1993; 165: 390-5.

11. F. M. Messahel. Comparison between open, mini-lap and laparoscopic techniques. Anaesthesia 1995 ; 50(10): 901- 4.

12. U. Berggen, T. Gordh, D. Grama . Laparoscopic versus open cholecystectomy : hospitalization, sick leave, analgesia and trauma responses .Br J Surg 1994; 81: 1362-5.

13. F.P. McGinn, A.J. Miles, M. Uglow. Randomized trial of Laparoscopic cholecystectomy and minicholecystectomy. Br J Surg 1995; 82: 1374-7.

14. J.J.T. Tat, W.Y. Lau, K.L. Leung . Laparoscopic versus mini incision cholecystectomy. Lancet 1993; 63: 291-5.

15. A. Novelli. Antimicrobial prophylaxis in surgery: The role of pharmacokinetics. J Chemother 1999;11(6):56572 .

16. G.L. Bennett, E.J. Balthazar. Ultrasound and CT evaluation of emergent gallbladder pathology. Radiol Clin North Am 2003 Nov; 41(6): 1203-16.

17. S. A. Cohen, J. H. Siegel. Biliary tract emergencies. Endoscopic and Medical management. Crit Care Clin 1995 Apr; 11(2): 273-94. 
Journal of College of Medical Sciences-Nepal,2011,Vol-7,No-3

18. D. I. Giurgiu, J. J. Roslyn. Treatment of gallstones in the 1990s. Prim Care 1996; 23(3): 497-513.

19. I. lambek, B. Arnesjo, O. Soreide. Correlation between gallstones and abdominal symptoms in a random population. Results from a screening study. Scand J Gastroenterol 1989 Apr; 24(3): 277-81.

20. P. Janowitz, W. Kratzer, T. Zemmler. Gallbladder sludge: spontaneous course and incidence of complications in patients without stones.Hepatology1994 Aug; 20 (2): 291
21. S. Elder, J. Qunin, Chourih, et al. Safety of laparoscopic cholecystectomy in a teaching services: A prospective trial. Surg Lap Endosc 1996;6(3):218-20.

22. S. H.Lim, I. Saleh, B. K. Poh. Laparoscopic Cholecystectomy: an audit of training programme. Aust NZ J Surg 2005;75(4):231-3.

23. G. M. Arain, A. Hassan, M. H. Randhawa, et al. Laparoscopic Cholecystectomy and its complications: a study of 1100 cases. Pak J Gastroentrol 1998;12(12):29-35 